\section{Denture-curing oven}

By Brian Williams, Retired GDP, Museum Volunteer and Honorary Secretary of the Lindsay Society: the History of Dentistry

Vulcanite became the denture-base material of choice for most people in the 1850s. It fitted better than carved ivory or bone, and was less costly than swaged gold, despite the royalties that had to be paid to the Goodyear Rubber Company for every denture made. With the lapse of the Goodyear patent in 1881 , vulcanite dentures became 'cheaper' falling to 'only' $£ 5$, which was still a week's wages for a labourer at the time!

Because vulcanite was not an ideal material for the wet environment of the mouth - it was porous and, over time, discoloured and became smelly - the hunt began for something better. Research by ICI in the 1920s and 1930s led to a number of 'plastics' being produced, but it was not until 1935 that the acrylic-resin Kallodent was launched.

The denture would be waxed up and invested in stone in the usual way. Once set, the wax would be boiled out using the lostwax technique to leave the hollow denture pattern buried deep within the dental flask.

An electric dental oven was used to dry and heat the flask to $140 \mathrm{C}$ over 14 hours under thermostatically controlled conditions. Great care was taken during the procedure to ensure all heat reached the flask by 'convection and none by conduction.' This was to stop any uneven contractions occurring within the stone and allow the whole mass to shrink, it was claimed, by no more than $0.165 \%$ during the whole of the drying process.

The solid door was closed by a simple catch. The plaque on it reads: 'Dental Equipment. This oven is built to the requirements of I.C.I. (Fertilizer and Synthetic Products) Ltd. For the use with Kallodent (Registered Trade Mark) No.8080'

Once removed from the oven, the hot unopened flask was injection moulded with Kallodent. An injection press was used to heat solid 'blank' 3/4-inch cylinders of Kallodent to approximately 200C, at which point the resin was soft enough to be injected under pressure through sprue holes into the denture pattern within the stone. The flask containing the soft Kallodent denture was allowed to cool and harden for at least 90 minutes before being

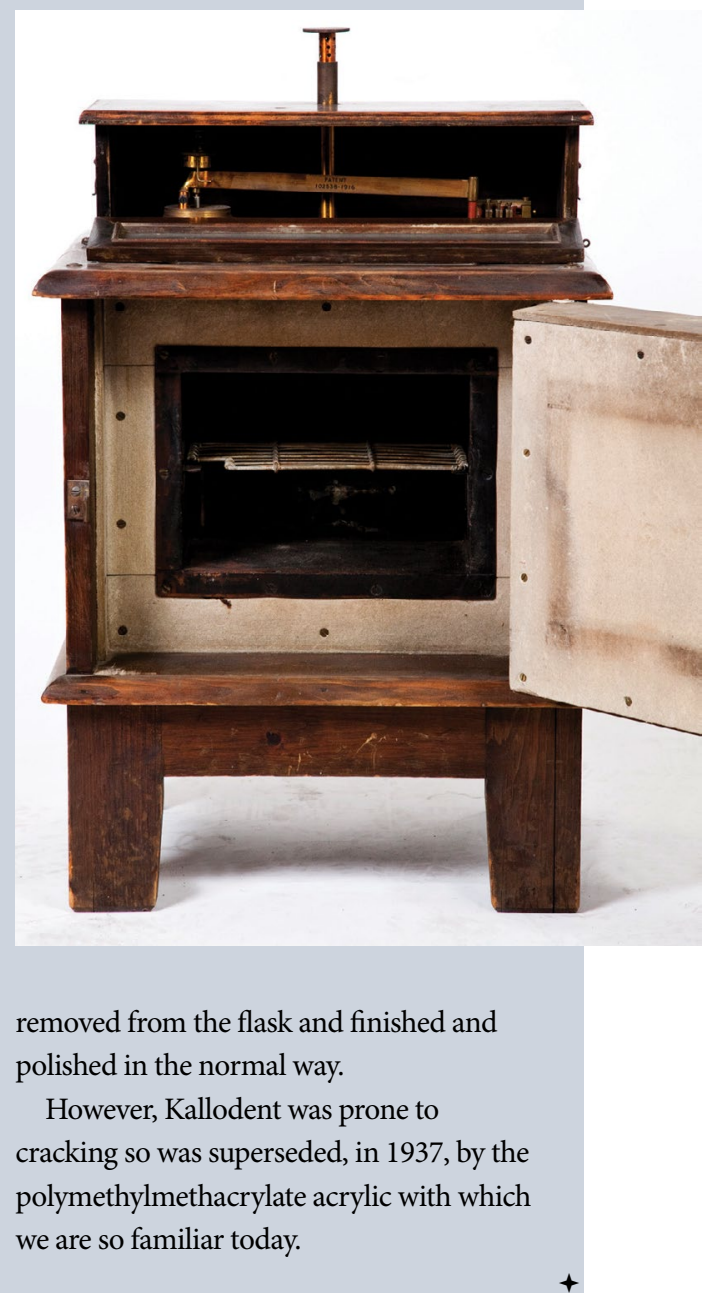

\title{
BDA supports Learning Disability Awareness Week
}

The British Dental Association (BDA)

supported Learning Disability Awareness

Week from 14-20 June by encouraging

all dentists and dental team members

to download a new, free set of Makaton prompt cards to help break down barriers to communications for dental patients.

To access the resource, visit the Makaton Library, create a free login and search for 'Your dental appointment': https://www. makaton.org/TMC/TMC/About_Makaton/ The_Makaton_Library.aspx.

Makaton is a unique language programme that uses symbols and signs alongside speech to enable people to communicate more effectively. All people with a learning disability should have the support they need to access dental care and this tool can be used to support communication in day-to-day practice.

To highlight these new resources, the BDA has collaborated on a short film highlighting the experience of someone with a learning disability visiting the dentist, available via YouTube: https://www.youtube.com/ watch?v=bqbm6ZfT7jE.

The film features Charlotte Waite, Senior Community Dentist and Chair of the BDA's England Community Dental Services Committee (ECDSC), and Gary Parker, an actor with a learning disability who is part of the MiXit theatre group.

This collaboration has been led by Health Education England, and supported by Amanda Glennon, a Makaton tutor and ambassador, and Helen Laverty MBE, University of Nottingham professional lead for learning disability nursing, and the BDA.

Charlotte Waite said: 'I was delighted to be asked to support this project. Figures provided by Health Education England indicate that there are over 1.2 million people in England who have a learning disability. It is also important to recognise that many adults, as well as children, will benefit greatly from communications tools like Makaton. A number of patients with a learning disability will visit a high street dentist. By taking some time to learn a few of these Makaton signs you will be enhancing your communication skills, as well as supporting your patients.

Many patients are anxious about visiting the dentist, and research has shown that those with learning disabilities also face extra barriers to dental care, including communications barriers, access problems, anxiety, sensory overload and the concerns of carers or their families, and some of these have been thrown into sharp relief by the COVID-19 pandemic.

Read Charlotte Waite's blog on Breaking down barriers to access: https://www.bda.org/ news-centre/blog/Pages/Breaking-downbarriers-to-care.aspx.

Find out more about the BDA's work on patients with learning disabilities: https://bda. org/about-the-bda/campaigns/oralhealth/ Pages/learning-disabilities.aspx. 